Full Length Articles

\title{
The interplay between oil and food commodity prices: Has it changed over time? is
}

\author{
Gert Peersman ${ }^{\mathrm{a}, *}$, Sebastian K. Rüth ${ }^{\mathrm{b}, \mathrm{c}}$, Wouter Van der Veken ${ }^{\mathrm{a}}$ \\ ${ }^{a}$ Ghent University, Department of Economics, Sint-Pietersplein 5, 9000 Gent, Belgium \\ ${ }^{\mathrm{b}}$ University of Erfurt, Faculty of Economics, Law and Social Sciences, Nordhäuser Str. 63, 99105 Erfurt, Germany

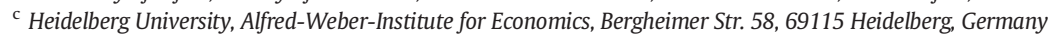

\section{A R T I C L E I N F O}

\section{Article history:}

Received 4 April 2020

Received in revised form 26 September 2021

Accepted 2 October 2021

Available online 27 October 2021

Repository data link: https://data.mendeley. com/datasets/4s363tdjxf/1/files/cdd74e1ab60e-4c4b-bf44-c2be42678ce9

\section{JEL classification:}

E31

F30

G15

Q11

Q41

\section{Keywords:}

Commodity markets

Food prices

Oil prices

Informational frictions

\begin{abstract}
A B S T R A C T
Using a structural time-varying-parameter Bayesian vector autoregression (TVP-BVAR) framework, this paper documents that oil price increases caused by oil supply disruptions did not affect food commodity prices before the start of the millennium, but had positive spillover effects in more recent periods and particularly in the era around the Great Recession. Likewise, shortfalls in global food commodity supply resulting from bad harvests have positive effects on crude oil prices since the early 2000s, in contrast to the preceding era. The econometric evidence suggests that these developments are not the consequence of the popular biofuels narrative and more likely the result of informational frictions about the global business cycle and information discovery in financialized commodity markets.
\end{abstract}

(c) 2021 The Author(s). Published by Elsevier B.V. This is an open access article under the CC BY-NC-ND license (http://creativecommons.org/licenses/by-nc-nd/4.0/).

\section{Introduction}

The prices of crude oil and food commodities have experienced rollercoaster rides in recent decades, and their comovement has varied considerably over time (Fig. 1). Specifically, several measures of time-varying unconditional correlations of the price changes that were negative in the 1990s, shifted into positive territory during the early 2000s, and decreased again after 2010.

A first possible explanation for the increased synchronization is a rise in the contribution of common demand factors to the variation of both commodity prices relative to the contribution of supply and idiosyncratic shocks. There are two popular

th This project received financial support from the Mecenaat portfolio of the National Bank of Belgium and the Ghent University Special Research Fund (BOF). The funding sources had no involvement in the study design; in the collection, analysis and interpretation of data; in the writing of the report; or in the decision to submit the article for publication.

* Corresponding author.

E-mail addresses: gert.peersman@ugent.be (G. Peersman), sebastian.rueth@uni-erfurt.de (S.K. Rüth), wouvdrve.vanderveken@ugent.be (W. Van der Veken). 
A. Oil and Food Commodity Prices

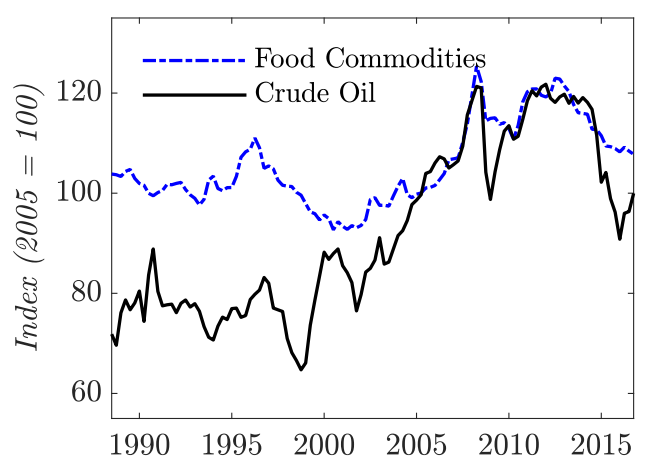

C. Commodity Markets Financialization

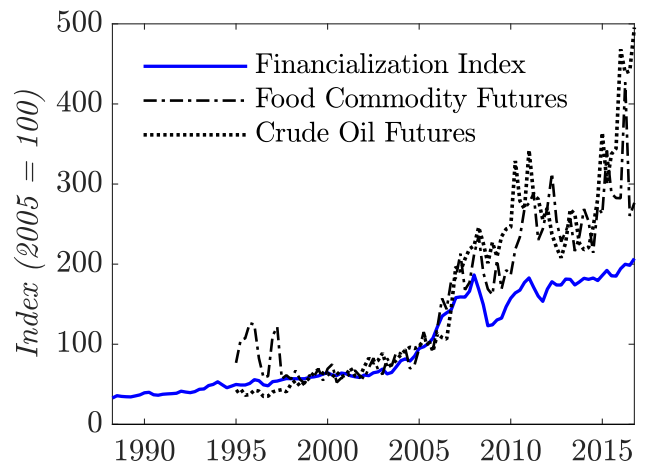

B. Price Correlations



D. Biofuels Consumption



\section{E. Macroeconomic Volatility}

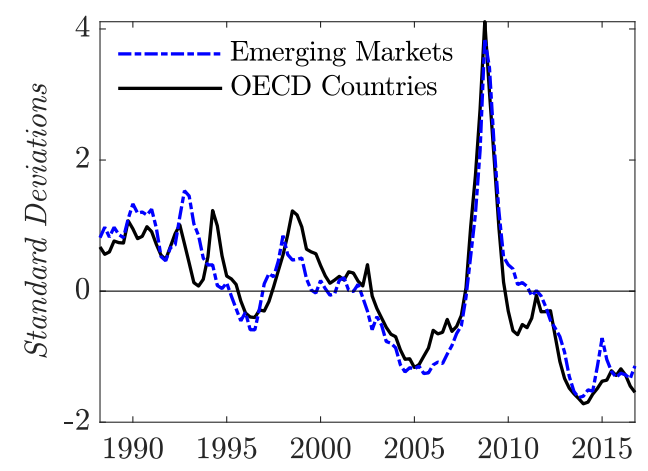

Fig. 1. Comovement of commodity prices and other stylized facts. Notes: Panel A shows (the natural logarithm of) crude oil and food commodity prices, indexed to $2005=100$. Food commodity prices are a weighted average of the prices of corn, soybeans, wheat and rice. The solid line and the shaded area in panel B denote kernel regression coefficients and the associated 95 percent confidence bands. The dotted line shows correlation coefficients for a sample split in $2003 \mathrm{Q} 4 / 2004 \mathrm{Q} 1$. The dashed line displays correlations derived from (lagged) 5-year rolling windows. These computations are based on the growth rates of the variables in panel A. The dotted and dash-dotted lines in panel C show the NYMEX trading volumes of crude oil WTI futures contracts and the corresponding CBOT aggregates for total corn, soybeans, wheat and rice futures, respectively. The solid blue line shows a commodity markets financialization index along the lines of Cheng and Xiong (2014). These time series are shown as an index with $2005=100$. Panel D represents indices $(2005=100)$ of biofuels consumption in the U.S. and on a global basis. Data sources and details on the construction of the global index can be found in appendix D. Panel E shows the standardized variance of macroeconomic shocks; the solid black line plots the unforecastable common component of a large set of macroeconomic variables for 22 OECD countries, as proposed by Mumtaz and Musso (2021). The dashed blue line plots macroeconomic volatility exclusively for emerging markets, as proposed by Miescu (2019). (For interpretation of the references to color in this figure legend, the reader is referred to the web version of this article.)

hypotheses that could rationalize this interpretation. On one hand, the stronger comovement may be induced by macroeconomic fundamentals; that is, global business cycle fluctuations that jointly induce shifts in oil and food commodity demand. A popular example is the high income growth in China and emerging economies at the beginning of the millennium (e.g., Hamilton, 
2009; Abbott et al., 2011). On the other hand, an increased relevance of demand factors may be the result of the worldwide financialization of commodity markets and the associated large capital inflows from the early 2000s onward, which is illustrated in panel C of Fig. 1 (see e.g. Lombardi and Van Robays, 2011; Tang and Xiong, 2012; Singleton, 2013; Cheng et al., 2015).

An alternative explanation-beyond any common demand narrative-is the existence of direct price spillover effects of idiosyncratic and/or supply shocks that, at the same time, became stronger since the 2000s. In this vein, the soaring biofuels revolution may have triggered (stronger) spillover effects of autonomous oil and food commodity shocks in recent periods. In particular, besides crude oil, agricultural sector output has increasingly been used as an input factor for the energy producing industry since the early 2000s. With a higher degree of substitutability, any shock affecting the price of one commodity will more likely shift the price of the substitute in the same direction, increasing their correlation. Numerous studies conclude that this has indeed been the case; that is, biofuels appear to have played an important role for an increased synchronization between oil and agricultural commodity prices. ${ }^{1}$

Notwithstanding the overwhelming support for price spillovers, several caveats apply to the methods that have been used. First, most empirical studies are based on reduced-form models that only explore unconditional comovement in the data. ${ }^{2}$ Accordingly, it is not possible to disentangle a rise in the comovement that is caused by common demand factors and stronger spillover effects as a result of biofuels, which requires a structural econometric framework.

Second, existing studies that evaluate changes over time are based on sample splits, such as the periods before and after the U.S. Energy Policy Act of 2005 to promote biofuels. However, the influence of biofuels does not necessarily represent a one-time structural break. The rise in the use of biofuels, namely, occurred over several years, which suggests a gradual transition process (Fig. 1, panel D). Moreover, since crude oil cannot be used as food, the relationship should depend on the relative level of both commodity prices. Specifically, substitution could only take place when the price of oil is equal or higher than the price of food commodities measured per unit of energy, and becomes non-operational when oil prices are below food commodity prices (Hassler and Sinn, 2016). Furthermore, the existence of a blend wall in the U.S.; that is, refineries are unable to blend more than 10 percent ethanol into gasoline, could weaken the relationship when the wall becomes binding (Tyner, 2010). These features suggest that the best modeling approach is one that allows for slow-moving but continuous changes, as well as for possible jumps and nonlinearities.

Moreover, there may have been other developments that could have led to a larger direct contagion between both commodity prices. For instance, the presence of a zero lower bound (ZLB) on nominal interest rates could imply that oil or food commodity price increases (decreases) result in lower (higher) real interest rates, which stimulate (contract) the economy and thus the demand for other commodities. Hence, also other commodity prices increase (decrease).

Another mechanism ignored so far is that, in the presence of informational frictions about the state of the world economy, the globalization and financialization of commodity markets since the 2000s could have resulted in enhanced spillovers. Sockin and Xiong (2015) develop a model in which commodity prices serve as signals of the strength of the economy for goods producers that do not perfectly observe fundamentals. In their model, commodity price shifts that are not the consequence of changes in economic activity can be misinterpreted as signals about the strength of the economy, causing producers to change their commodity demand. Since goods producers cannot differentiate a price increase caused by an unfavorable supply shock from an increase triggered by an expansion in the global economy in real time, they partly attribute the supply shock to a demand shock. As a result, they raise their commodity demand despite the price increase, which amplifies the impact of the supply shock on commodity prices.

This mechanism is conceivable to also affect other commodities. For example, an unfavorable oil supply shock that raises oil prices may be interpreted as a signal of global economic strength, increasing the demand for food commodities and their prices. Clearly, the extent of informational frictions and such spillover effects likely vary over time. In particular, the globalization (e.g. the participation of several emerging countries) should have increased informational frictions over time, while the financialization of commodity markets since the 2000s has facilitated and encouraged information discovery in these markets. Furthermore, in the presence of informational frictions and information discovery in commodity markets, the responsiveness of commodity demand to price signals increases in periods when the volatility of unobserved global economic activity is elevated. This was, for example, the case in the era surrounding the Great Recession (Fig. 1, panel E). Intuitively, price changes are more likely reflecting changes in unobserved economic activity when the variance of such fluctuations is high relative to the variance of all other possible determinants of commodity prices. In sum, studies that attribute the synchronization of oil and food commodity prices to biofuels may be spuriously picking up informational frictions and price discovery in commodity markets.

We use structural time-varying-parameter BVAR models with stochastic volatility to investigate whether price spillovers of oil and food commodity supply shocks have changed over time. Our analysis incorporates several innovations to address the above caveats. First, rather than imposing an arbitrary sample split, all model coefficients can evolve continuously over the sample period. The approach also accommodates discrete shifts and several possible nonlinearities. Second, we isolate price changes that are caused by exogenous oil and food commodity supply shocks, which allows us to estimate causal links between both commodity prices that can be interpreted as spillover effects. Since we identify oil and food supply shocks, we can examine spillovers in both directions, which contrasts with studies that only allow for a unidirectional pass-through of oil to food prices (e.g. Hertel and

\footnotetext{
1 Tyner (2010) documents a link between oil and corn prices since 2006 that did not exist historically and attributes it to biofuels markets, while Hertel and Beckman (2012) find that increases in biofuels production have resulted in volatility spillovers from energy to food markets. For a review of the biofuels-related price transmission literature, see Serra and Zilberman (2013). For a theoretical exposition, see Hassler and Sinn (2016).

2 Examples are reduced-form Granger causality tests (e.g. Avalos, 2014) and reduced-form or semi-structural VARs (e.g. Baumeister and Kilian, 2014).
} 
Beckman, 2012). Finally, we also estimate the time-varying spillovers of both shocks on metals and minerals commodity prices and on the prices of agricultural raw materials. Since both commodity classes should not be affected by the biofuels revolution, we can learn more about the role of biofuels for the time variation. This cross-examination can be compared with a differencein-difference approach, where the spillovers between food and oil prices are the treated variables, while the spillovers of both shocks on the prices of metals, minerals and agricultural raw materials are control variables.

The main findings are as follows. First, oil price increases caused by shortfalls in oil supply did not affect food commodity prices before the early 2000s, but had positive spillover effects in the more recent era, particularly in the years surrounding the Great Recession. Second, disruptions in food commodity supply did not have spillover effects on oil prices prior to the start of the millennium, but do so since. Price spillovers thus exist in both directions. Third, we document that price spillovers have continuously built up over the sample period, but have gradually decreased again since 2010, which is a pattern that cannot be captured by sample splits. Fourth, it is unlikely that the expansion of biofuels is the key source of the time variation. Specifically, we find very similar time-varying spillovers of both supply shocks on metals and minerals commodity prices and, to lesser extent, on prices of agricultural raw materials. We show that it is also unlikely that the ZLB has raised the spillover effects.

Finally, we argue that the concurrent spillovers between multiple commodity prices are more likely the consequence of heightened informational frictions in financialized commodity markets. Three additional empirical observations support this hypothesis. First, the model of Sockin and Xiong (2015) predicts that informational frictions should also enhance the impact of supply shocks on the commodity's own price. This is exactly what we find: a (one percent) negative food commodity supply shock has led to a much stronger rise in food commodity prices since the 2000s. Similarly, the impact of oil supply disruptions on oil prices was much higher in periods where we also find a stronger pass-through to other commodity prices. Second, misinterpretation of commodity supply shocks should in real time have been reflected in measures of expected economic activity. We indeed find simultaneous time variation in the impact of both supply shocks on several indicators of expected economic activity that is consistent with misinterpretation of the shocks; that is, these indicators responded more optimistically to unfavorable shocks in real time. Finally, local projections estimations reveal that the extent of global macroeconomic volatility, the degree of financialization and particularly the interaction of both phenomena had a significantly positive impact on the magnitudes of the spillover effects. This finding is, again, consistent with the mechanism described in Sockin and Xiong (2015).

The paper is structured as follows. Section 2 describes the methodology, data and identification strategy. Section 3 presents the baseline results. Section 4 evaluates the role of biofuels and the ZLB. Section 5 examines the informational frictions hypothesis, and Section 6 concludes.

\section{Methodology}

We use BVARs that allow for time-varying parameters and stochastic volatility to accommodate the continuous evolution of the structure of commodity markets (Baumeister and Peersman, 2013). The drift in the parameters accommodates possible nonlinearities or changes in the model's lag structure, while the multivariate stochastic volatility captures heteroscedasticity of innovations and nonlinearities in the simultaneous relations between the variables in the system. Another advantage of VAR models is that they allow to identify exogenous oil and food commodity supply shocks, which is crucial to properly examine spillover effects.

\subsection{TVP-BVAR for crude oil and food commodity markets}

As the benchmark, we model the behavior of crude oil and food commodity markets in the following TVP-BVAR(p) framework along the lines of Primiceri (2005):

$$
\boldsymbol{y}_{t}=\boldsymbol{C}_{t}+\sum_{l=1}^{p} \boldsymbol{B}_{l, t} \boldsymbol{y}_{t-l}+\boldsymbol{u}_{t} \equiv \boldsymbol{X}_{\boldsymbol{t}}^{\prime} \theta_{\boldsymbol{t}}+\boldsymbol{u}_{t}
$$

where $\boldsymbol{y}_{t}$ is a vector of observables, $\boldsymbol{C}_{t}$ captures time-varying regression intercepts and the matrices $\boldsymbol{B}_{l, t}$ comprise the lag coefficients of the VAR for lag $l=1, \ldots, p$. We stack the time-varying lag parameters and intercepts into $\boldsymbol{\theta}_{\boldsymbol{t}}$, while $\boldsymbol{X}_{\boldsymbol{t}}$ includes lagged realizations of $\boldsymbol{y}_{t}$ and a vector of constants. The vector $\boldsymbol{u}_{t}$ in the observation equation contains unconditionally heteroscedastic, unobservable innovations with variance-covariance matrix $\boldsymbol{\Omega}_{t}$. Technical details on the estimation are discussed in the (online) supplementary appendix A of this paper.

To study the spillover effects of oil supply shocks, $\boldsymbol{y}_{t}$ contains i) global crude oil production $q_{t}^{\text {oil }}$, ii) the price of crude oil $p_{t}^{\text {oil }}$ and iii) the price of another commodity $p_{t}^{j}$. The latter is, in turn, an index of food commodity prices $p_{t}^{\text {food }}$, metals and minerals prices $p_{t}^{\text {metal }}$, and prices of agricultural raw materials $p_{t}^{\text {arm }}$. Similarly, to estimate the pass-through of food commodity supply shocks, $\boldsymbol{y}_{t}$ includes i) an index of global food production $q_{t}^{\text {food }}$, ii) food commodity prices $p_{t}^{\text {food }}$ and iii) respectively $p_{t}^{\text {oil }}, p_{t}^{\text {metal }}$ and $p_{t}^{\text {arm }}$. All variables are transformed to quarter-on-quarter growth rates by taking the first difference $\Delta$ of their natural logarithm. The sample period is 1974Q1-2016Q4. The first 58 quarters are used as a training sample to initialize the priors for the actual sample period, which starts in 1988Q3 (see appendix A for details). To allow for sufficient lags in the propagation of structural innovations, we set $p=6$ quarters. In sum, as the benchmark, we estimate six parsimonious TVP-BVAR(6) $\operatorname{models:} \boldsymbol{y}_{t}=\left[\Delta q_{t}^{\text {oil }}, \Delta p_{t}^{\text {oil }}, \Delta p_{t}^{\text {food }}\right]^{\prime}$, 
$\boldsymbol{y}_{t}=\left[\Delta q_{t}^{\text {oil }}, \Delta p_{t}^{\text {oil }}, \Delta p_{t}^{\text {metal }}\right]^{\prime} \quad$ and $\boldsymbol{y}_{t}=\left[\Delta q_{t}^{\text {oil }}, \Delta p_{t}^{\text {oil }}, \Delta p_{t}^{\text {arm }}\right]^{\prime}$ for oil supply shocks, and $\boldsymbol{y}_{t}=\left[\Delta q_{t}^{\text {food }}, \Delta p_{t}^{\text {food }}, \Delta p_{t}^{\text {oil }}\right]^{\prime}, \quad \boldsymbol{y}_{t}=$ $\left[\Delta q_{t}^{\text {food }}, \Delta p_{t}^{\text {food }}, \Delta p_{t}^{\text {metal }}\right]^{\prime}$ and $\boldsymbol{y}_{t}=\left[\Delta q_{t}^{\text {food }}, \Delta p_{t}^{\text {food }}, \Delta p_{t}^{\text {arm }}\right]^{\prime}$ for food commodity supply shocks.

Since TVP-BVARs are highly parameterized, we limit the number of endogenous variables for the benchmark estimations to three and estimate separate models for both shocks. The reason is that the underlying data generating process requires several lags (Hamilton and Herrera, 2004; De Winne and Peersman, 2016). The correlation between the oil and food supply shocks obtained from the separately identified VARs is very low (0.1) and statistically not different from zero. Time-varying correlations of both shocks likewise turn out to be insignificant (appendix B). Hence, even when the shocks are identified in separate VARs, we obtain uncorrelated structural innovations. In the appendix, we show that the results are robust when we estimate five-variables TVP-BVARs with less lags in which both shocks are identified simultaneously, when we include measures of global (expected) economic activity and/or global inflation, and when we estimate linear VARs based on sample splits and variables in levels.

\subsection{Data}

$p_{t}^{\text {oil }}$ is the nominal U.S. refiners' acquisition cost of imported crude oil, while $q_{t}^{\text {oil }}$ is global crude oil production. Both series are standard in the oil literature and are collected from the U.S. Energy Information Administration (EIA). $p_{t}^{\text {metal }}$ and $p_{t}^{\text {arm }}$ are, respectively, a price index of metals and minerals commodities (referred to as a metals price index) and agricultural raw materials, both provided by the World Bank. We use nominal price variables, which is standard in the finance literature and most appropriate to study the pass-through to other prices. Note, however, that the results are quasi identical for real prices (appendix B).

For food commodity markets, we follow De Winne and Peersman (2016). $q_{t}^{\text {food }}$ is a composite quarterly global food production index based on harvest data of 192 countries. The index is a caloric weighted aggregate of the harvests of the four most important staple food items: corn, wheat, rice and soybeans. These commodities are traded in integrated global markets, and account for roughly 75 percent of the caloric content of food production worldwide. $p_{t}^{\text {food }}$ is the corresponding price index measured in U.S. dollars and made available by the IMF. By aggregating the staples, the implicit assumption is that their calories are substitutes. Since there is strong comovement between the prices of the staples, substitution possibilities are conceivably large such that the aggregate outcome characterizes the disaggregated markets reasonably well. Nevertheless, we also show disaggregate results in appendix C.

\subsection{Identification of oil and food supply shocks}

To examine spillovers, it is crucial to disentangle idiosyncratic supply shocks from (common) demand shocks. Therefore, in this paper we isolate price fluctuations that are exogenous and entirely supply driven, which contrasts the bulk of studies that analyze the link between oil and food markets (see Erten and Tuzcuoglu, 2018, for a notable exception).

We follow the approach of Baumeister and Peersman (2013) and subsequently used by many others in the oil literature to identify exogenous oil supply shocks, which is based on so-called sign restrictions that are imposed on the contemporaneous impact matrix of the shocks. Specifically, oil supply shocks are identified as the innovations in global oil production that move oil prices on impact in the opposite direction. Conversely, all shifts in oil production that move oil prices instantaneously in the same direction are not considered as supply shocks. This sign restriction corresponds to a shift of an upward-sloping oil supply curve along a downward-sloping oil demand curve and is sufficient to isolate oil supply shocks in the TVP-BVAR. Notice that no constraints are imposed on the responses of food prices, metals prices, or the prices of agricultural raw materials after the shock, which are determined by the data. Furthermore, we only keep candidate draws that feature a single supply shock in the system; that is, all other shocks do not move prices and quantities in the oil market in opposite directions on impact. ${ }^{3}$

Since we rely on realized global oil production volumes and prices for identification, we take the stance that our econometric model is ex post capable of recovering supply shocks. By contrast, market participants do not have a complete information set in real time. They can only observe oil prices, since global oil production outcomes are published with a time lag and are subject to revisions. Therefore, misinterpretation about the sources of commodity market movements in real time is conceivable and could be reflected in the response of oil prices to the shock and the price elasticity of oil demand. In fact, we will explore this feature to evaluate the presence of informational frictions in Section 5.

In contrast to the oil supply shocks, we can identify structural food supply shocks by simply imposing a recursiveness assumption (De Winne and Peersman, 2016; Peersman, 2021). We explore the fact that there is a time lag of at least one quarter (i.e. 3 to 10 months) between the planting and harvesting of cereal commodities, while harvest volumes are subject to shocks that are unrelated to the economy, such as weather variation or crop diseases. Specifically, the time lag of at least one quarter between the decision to produce (planting) and the actual production (harvest) implies that food producers are able to immediately respond to changes in demand by adjusting their planting volumes. Yet, for the actual production volume, this is not possible due to the

\footnotetext{
3 Sockin and Xiong (2015) argue that, in the presence of informational frictions, agents cannot disentangle supply and demand shocks in real time. Hence, through its informational role, an increase of commodity prices caused by a supply shock can be interpreted as a signal of economic strength, which may raise commodity demand. However, as long as the rise in demand is smaller than the negative cost effect of a price rise on demand, the supply shock still results in a negative comovement between production and prices, which is consistent with the restriction imposed to isolate oil supply shocks. On the other hand, if this informational effect dominates the negative cost effect; that is, the oil supply shock shifts oil production and prices in the same direction, such shocks are (wrongly) identified as oil demand shocks, but in this paper we are not interested in demand shocks.
} 
time lag. The reduced-form innovations to food production in the TVP-BVAR can thus be considered as food supply innovations that are orthogonal to developments in economic and financial markets conditions. Hence, ordering the quarterly food production index first in a block-recursive identification scheme, recovers food supply shocks. Notice that the responses of all the variables in the model are left unrestricted.

\section{Interplay between oil and food commodity prices}

Fig. 2 shows the benchmark results. Panel A displays the impact over time of one standard deviation adverse oil and food commodity supply shocks on all the variables that are included in the TVP-BVARs. This is the conventional way to report the results of TVP-BVARs. Since the size of both (one standard deviation) shocks has varied considerably over the sample period, in panel B, we show for each variable the changes over time of the impact of a normalized supply shock. Specifically, for each period $t$ we show the difference between the impact of a one percent decline in oil (food) production and the impact in a benchmark period. For the latter, we systematically select the quarter in the sample with the lowest normalized (median) impact or pass-through. Put differently, the figures show the estimated time variation in the own and cross-price responses to both shocks, along with credible sets. Notice that we only show the contemporaneous effects (within the quarter of the shock). Conclusions at longer horizons (by constructing impulse response functions) are the same and available on request.

As can be observed in Fig. 2, unfavorable oil supply shocks did not affect food commodity prices before the start of the millennium. If anything, the comovement of oil and food commodity prices in response to the shocks was negative. However, since the 2000s, we observe positive spillover effects on food commodity prices. Moreover, these spillovers gradually increased over the years, reaching a peak around 2008. In particular, in 2008, a typical oil supply shock triggered a rise in crude oil prices of 14 percent and, at the same time, resulted in a rise of food commodity prices by roughly 5 percent. This is also reflected in the time variation shown in the second column; that is, the price response compared to the benchmark quarter in the mid 1990s is for many years significantly larger. At its peak, there is a positive spillover effect and time variation for more than 90 percent of the posterior draws. Finally, the spillover effects became again more subdued in the years after the Great Recession.

A similar pattern can be observed for the impact of food commodity supply shocks on oil prices. Specifically, bad harvests that resulted in food commodity price increases had a negative impact on the price of crude oil in the 1990s, which is consistent with a reduction in the demand for oil in periods of lower economic activity (De Winne and Peersman, 2016, 2021). However, since the second half of the 1990s, the spillover effects switched sign to become positive. Again, there was a gradual increase of the spillovers during the 2000s, which reached a peak in 2008. Even though the uncertainty is high, the magnitudes are strong. A supply shock that augmented food commodity prices by 3.5 percent in 2008, also resulted in a rise of crude oil prices by 2.4 percent. Compared to the early 1990s, the impact of a one percent decline in global food production on crude oil prices was approximately 1.2 percentage points larger in 2008, while more than 90 percent of the posterior draws suggest a larger effect over time.

The spillover effects in recent periods are consistent with numerous studies that have documented increased synchronization between oil and agricultural commodity prices (e.g. Tyner, 2010; Avalos, 2014). In contrast to these studies, which typically examine unconditional comovement in the data, we show that the stronger correlation also exists conditional on idiosyncratic supply shocks. We also find that the synchronization has been a gradual process, rather than a structural break. Moreover, we document spillovers in both directions. This observation is important because it suggests that the comovement is not the consequence of a stronger unidirectional pass-through of oil to food prices, for example, due to the mechanization of agriculture or the rising relevance of energy intensive inputs in agricultural production.

\section{The role of biofuels markets and the ZLB}

Now we examine two popular explanations to rationalize the spillover effects in recent periods; that is, developments in biofuels markets and the presence of the ZLB on nominal interest rates. We infer that neither mechanism can be the key reason for the price spillovers.

\subsection{Biofuels markets and the pass-through to other commodity prices}

At first sight, developments in biofuels markets are consistent with the time variation. The U.S. Energy Policy Act of 2005, which required motor fuels to contain a minimum amount of fuel coming from renewable sources, resulted in a boost of ethanol production (Avalos, 2014). Around the same time, the expansion of European biodiesel production resulted in crowding out of the wheat area by oilseeds. Hence, the gradual rise of spillover effects, with an acceleration in the period 2005-2008, is consistent with the biofuels narrative. Also the subsequent decline can potentially be explained by biofuels. On one hand, oil prices collapsed much more than food commodity prices (see Fig. 1), and since oil cannot be used as food, substitution between both commodities is not possible when oil prices are below food commodity prices. On the other hand, since U.S. refineries were unable to blend more than 10 percent ethanol into gasoline at that time, due to the so-called blend wall, substitution between both commodities became more difficult, which may have weakened the link between both prices (Hertel and Beckman, 2012).

Nevertheless, the concurrent developments in biofuels markets do not imply that they are the main reason for the time variation. For example, given the limited use of biofuels in earlier decades, it is surprising that the rise of spillovers already started in the 1990s. Moreover, there could have been other transformations in commodity markets that give rise to a larger contagion 
A. One Standard Deviation Shock

Oil Supply Shock
Food Supply Shock

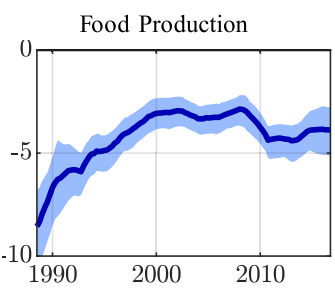

Oil Prices
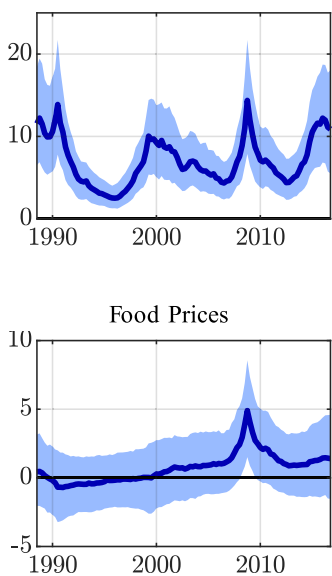

Metals \& Minerals Prices
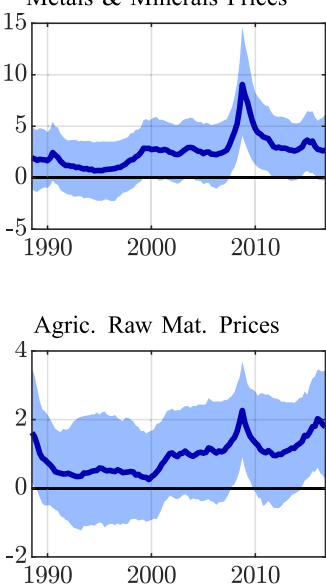

Oil Prices

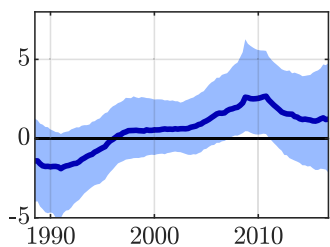

Food Prices

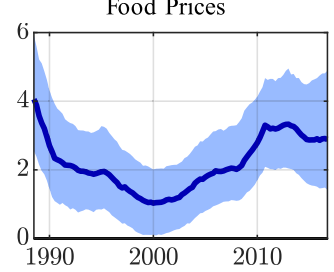

Metals \& Minerals Prices

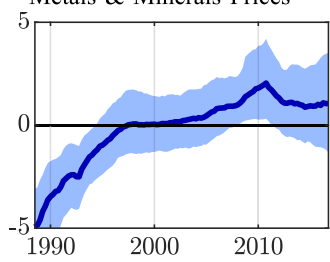

Agric. Raw Mat. Prices

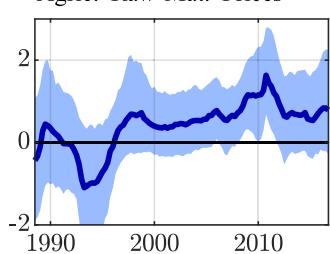

\section{B. Normalized Time Variation}

Oil Supply Shock

Food Supply Shock
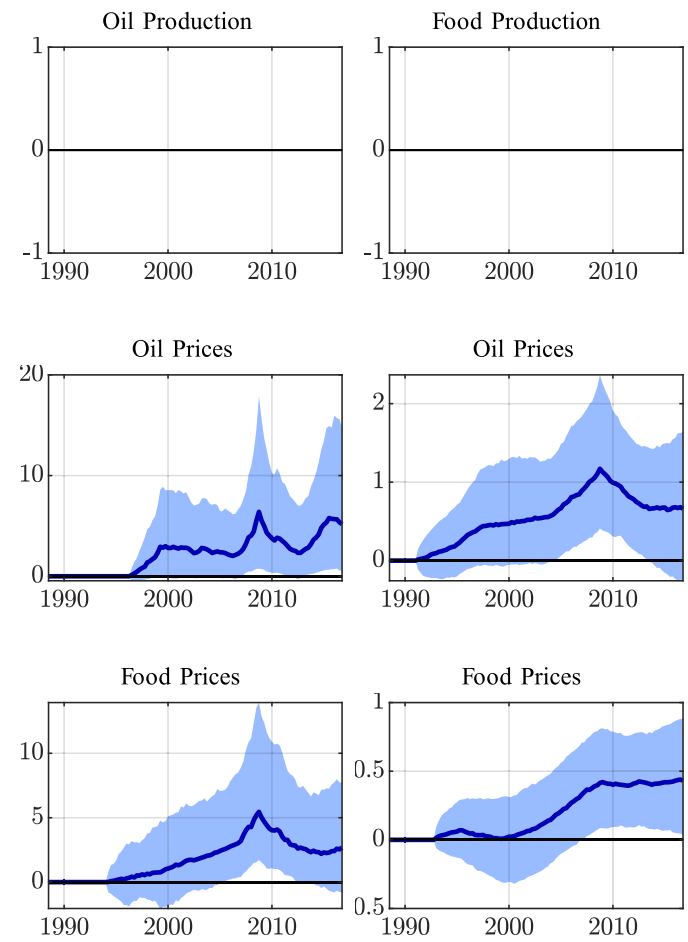

Metals \& Minerals Prices

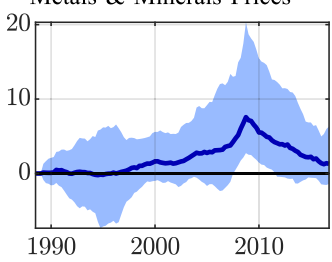

Metals \& Minerals Prices

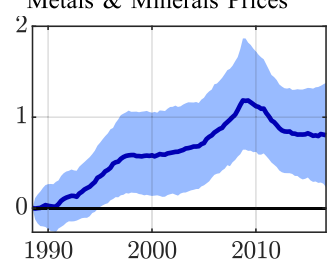

Agric. Raw Mat. Prices

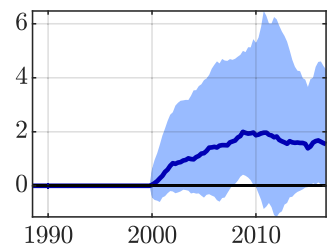

Agric. Raw Mat. Prices

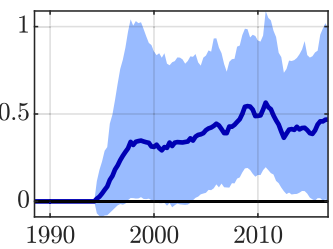

Fig. 2. Time-varying effects of oil and food supply shocks: benchmark results. Notes: Panel A shows the contemporaneous impact of a one standard deviation shortfall in the production of oil (first column) and food (second column) based on the TVP-BVARs. Panel B shows the time variation in these responses, calculated as the change in the contemporaneous response (normalized to represent a 1 percent production shortfall) over time relative to a benchmark quarter. The benchmark quarter is selected as the quarter with the lowest median (normalized) response. The shaded areas are the 16th and 84th percentile credible sets.

between oil and food commodity prices. To address this issue, we examine the pass-through of both supply shocks to the prices of metals commodities and agricultural raw materials. If the increased use of food commodities to produce energy goods is the key source of the spillovers, we should not-or to a much lesser extent-observe such time variation for commodities that are not related to the enhanced substitution possibilities. This holds for metals commodities and agricultural raw materials. Both commodity classes are not used to produce energy and neither do they provide calories that can substitute for food commodities. 
The impact of oil and food commodity supply shocks on metals commodity prices and the price of agricultural raw materials is shown in the bottom rows of Fig. 2. The time-varying spillover effects are remarkably similar to those between oil and food commodity prices. There is a gradual increase of the normalized spillover effects over time. The results indicate that metals commodity prices are slightly more subject to the enhanced pass-through than agricultural raw materials. While unfavorable food supply shocks had a negative effect on metals prices in the early 1990s, the spillovers have been positive since the 2000s. Also the timing of the peak of the spillovers to the prices of the control group of commodities corresponds to the peak of spillovers between oil and food commodity prices. Notice that the magnitudes of the changes over time are also very similar, in particular for metals prices. In sum, the striking analogous time-varying spillovers on metals and agricultural raw materials commodity prices, which are not substitutable with either food or oil, raise questions about the validity of studies that attribute the strengthened relationship between food and oil commodity markets to the biofuels revolution. At least, it cannot be the main reason.

\subsection{Monetary policy response and the ZLB}

The ZLB on nominal interest rates could be raised as an explanation for spillovers across various commodities. Datta et al. (2021) argue that the changed behavior of U.S. real interest rates at the ZLB results in a positive correlation between the returns of oil and U.S. equity. In their model, oil price increases (decreases) at the ZLB result in lower (higher) real interest rates because, at the ZLB, the policy rate does not or cannot respond to stabilize the inflationary effects. Consequently, the monetary expansion could limit or even overturn the conventional recessionary impact of oil price increases. Accordingly, positive cross-commodity price spillovers could emerge as the expansion spurs demand for commodities.

There are several reasons why the ZLB is unlikely the source of the time variation we observe. First, Datta et al. (2021) show that equity and crude oil prices can only move in the same direction after an oil supply shock when the shock is assumed to be very short-lived, which contradicts the persistent response of oil production after the oil supply shocks that we have identified. Second, it is conceivable that central banks were still able to respond at the ZLB by using unconventional policy tools. Third, the pattern of the spillovers does not coincide with the ZLB explanation. On one hand, the spillover effects started to build up already in the early 2000s, which precedes the ZLB in advanced economies by many years. On the other hand, the strength of the spillovers peaks around 2008 and weakens substantially in the following years. This indicates that the period of the ZLB in advanced countries is characterized by dissipating spillovers rather than increasing spillovers.

Still, we formally explore the ZLB hypothesis by estimating augmented TVP-BVARs that add the shadow rate of Wu and Xia (2016) to proxy for the policy stance of the Fed during the ZLB. The responses of the shadow rate to adverse commodity supply shocks are shown in Fig. 3. While the point estimates are close to zero for oil supply shocks before the Great Recession, the Fed tended to ease somewhat in response to food supply shocks. Hence, there is no evidence of a systematic tightening after adverse commodity supply shocks outside the ZLB. In the quarters around the Great Recession, however, we do observe a contraction of the Fed's policy stance, which is the opposite of the ZLB hypothesis of commodity price synchronization.

\section{Informational frictions in commodity markets}

It is widely recognized that centralized trading in asset markets serves as a platform to aggregate dispersed information of market participants. Building on this principle, Sockin and Xiong (2015) show that commodity prices could serve as signals of the strength of the economy when market participants (goods producers) cannot observe fundamentals. For instance, a rise in commodity prices may signal a stronger economy. However, since fundamentals are not observed directly, other sources of price shifts can be misinterpreted as signals about the state of the economy, causing some participants to change their commodity

\section{A. Oil Supply Shock}

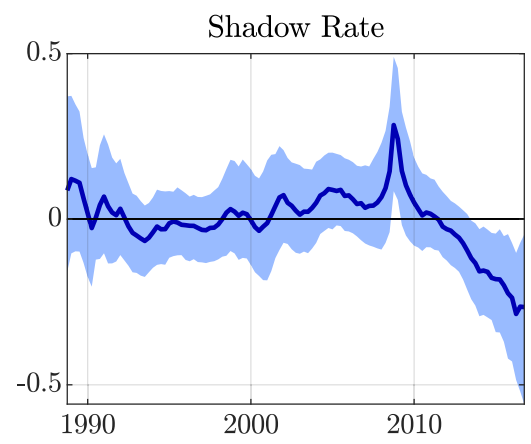

\section{B. Food Supply Shock}

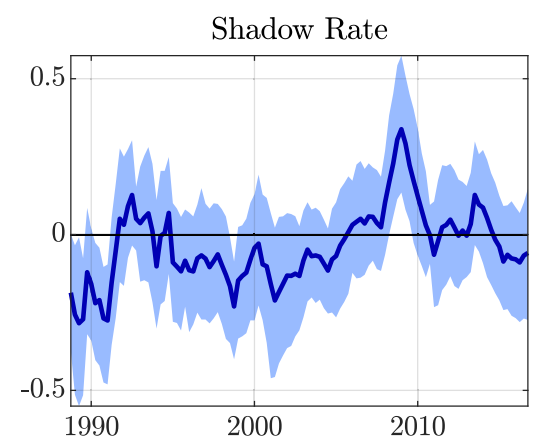

Fig. 3. Time variation in the Fed's reaction to commodity supply disruptions. Notes: The figure shows the contemporaneous impact of a one standard deviation shortfall in the production of crude oil (panel A) and food commodities (panel B) based on extended TVP-BVARs. Both TVP-BVARs augment the baseline models by the shadow rate of $\mathrm{Wu}$ and Xia (2016), and are estimated using four lags. The training sample uses 69 quarters such that the actual sample starts in 1988Q4. The shaded areas are the 16 th and 84 th percentile credible sets. 
demand. For example, an oil supply shock that raises oil prices may be misinterpreted as a signal of a strong economy, increasing the demand for commodities. Hence, also the prices of non-oil commodities could increase as a result of the oil supply shock.

The existence of informational frictions in commodity markets is realistic. On the supply side, global oil production volumes are published with a lag of approximately 3 months by the EIA and are regularly significantly revised. The EIA often even fails to accurately measure domestic oil production for the current and previous year. ${ }^{4}$ Likewise, the richest source of global food production is provided by the Food and Agriculture Organization (FAO), which publishes only annual production data with a delay of roughly one year. Akin to the EIA's oil projections, the U.S. Department of Agriculture (USDA) projections on global grain production are subject to substantial revisions (see De Winne and Peersman, 2016, Figure 8).

Even if we take the stance that agents have complete information about supply conditions in real time, they still lack information about global demand, which makes it impossible to determine the source of commodity price fluctuations in real time. A striking example for informational frictions that commodity market observers face is offered by the June 24-25, 2008 FOMC meeting, during which vice chairman Donald Kohn put his market assessment as follows:

"I think the upside risks result from two additional areas of uncertainty. One area is commodity prices [...] I really don't think we have much of a clue about the cause of the spike in oil prices this year. [...] Absent any surprises, futures market quotes ought to be the best guide, but what we don't understand can fool us, especially when so much of the relevant information involves emerging market economies, where data are sparse and of questionable value."

A natural question is whether informational frictions can explain the time variation of commodity market dynamics. In the remaining of this section, we first argue that this is indeed possible. We then provide three additional empirical observations supporting this hypothesis.

\subsection{Time variation of spillover effects}

The timing of the enhanced spillover effects is consistent with the informational frictions hypothesis. First, the financialization of commodity markets increased monotonically over time and accelerated in the early 2000s (Fig. 1). This has facilitated information discovery. In particular, since trading physical commodities in spot markets is subject to several distortions such as heterogeneity in quality, storage and transportation costs, the lower trading costs and highly standardized futures contracts have facilitated the aggregation of dispersed information among market participants (Sockin and Xiong, 2015). As a result, the centralized futures prices of key commodities have been widely used as barometers of the global economy since the start of the millennium (Cheng and Xiong, 2014).

Second, even though the financialization of commodity markets and a constant degree of informational frictions about the state of the economy is a sufficient condition to raise spillover effects, informational frictions have likely also increased since the 1990s, and particularly during the 2000s (Cheng and Xiong, 2014). Specifically, there is a broadly held perception that the globalization of commodity markets and increasing importance of commodity demand from rapidly growing emerging economies has made it more difficult to assess the strength of the global economy in this period. As mentioned in the above quote of Donald Kohn, reliable and timely statistics about economic activity in emerging countries were scarce. A notable example for a misinterpretation of the state of the global economy and growth in emerging countries during this episode was the ECB's decision to raise interest rates when the Great Recession was unwinding in July 2008. According to Jean-Claude Trichet at the press conference, the ECB considered the high prices of commodities as a key factor for their decision:

"While moderating, growth in the world economy is expected to remain resilient, benefiting in particular from continued robust growth in emerging economies. [...] Risks to price stability at the policy-relevant medium-term horizon remain clearly on the upside and have increased further over the past few months. These risks include notably the possibility of further increases in energy and food prices."

Speaking at the Council on Foreign Relations on May, 8 2008, John Lipsky-at the time First Deputy Managing Director of the IMF-shared a similarly sanguine prospect of bullish times being down the road for emerging economies:

"Demand for energy and commodities has remained robust reflecting especially the strong growth in emerging and developing economies, led by China and India. [...] The prospect of a continued relatively strong expansion in these economies suggests that demand growth for energy and commodities will remain solid, even as global growth is slowing."

Third, Sockin and Xiong (2015) show that the informativeness of the price signal and the associated responsiveness of commodity demand to price changes increase when the contribution of unobserved global macroeconomic shocks to the variance of commodity prices increases relative to the contribution of other commodity market shocks. To that end, fluctuations in global economic activity and the variance of macroeconomic shocks were particularly high in the era surrounding the Great Recession (see Fig. 1). For example, Baumeister and Peersman (2013a) find that the contribution of global economic activity shocks to the forecast error variance of oil prices was about 30 percentage points higher in the Great Recession compared to the preceding and subsequent years. Due to the high signal-to-noise ratio of commodity prices about the

\footnotetext{
${ }^{4}$ See the substantial revisions on current and previous calendar year projections in a retrospective review of Annual Energy Outlooks: https://www.eia.gov/outlooks/ aeo/retrospective/pdf/retrospective.pdf.
} 
state of the economy in this era, it is hence conceivable that market participants believed that price changes were more likely triggered by real economy shocks, which enhances spillover effects of supply disruptions. Indeed, the period around the Great Recession is exactly when we observe the strongest spillover effects of commodity supply shocks. In sum, the narrative of the time-varying spillover effects is consistent with the hypothesis of informational frictions and price discovery in financialized commodity markets.

\subsection{Own-price elasticities of commodity demand}

Another prediction of the model of Sockin and Xiong (2015) is that informational frictions should increase the impact of supply shocks on the own price of a commodity, which corresponds to a decline in the price elasticity of commodity demand. Consider, for example, an adverse supply shock in the global oil market that raises oil prices. Because this price increase is partly interpreted as a signal of a stronger economy, there is an increase in oil demand and thus an additional increase in the price of oil triggered by the shock through a feedback effect. Thus, if informational frictions are the source of the time-varying spillover effects, we should observe similar time variation for the effects of food and oil supply shocks on their own prices.

As can be observed in Fig. 2, this is also exactly what has happened: both shocks have a stronger impact on the own price in recent periods compared to earlier decades. Moreover, the pass-through was particularly strong in the era surrounding the Great Recession. We are not aware of another mechanism that can explain this concurrent time variation. In fact, when there is a rise in the substitutability of a commodity (i.e. the biofuels narrative), the own price elasticity should increase rather than decrease because it is easier to switch to the alternative. The time variation in the own-price elasticities of the demand for food commodities and oil hence supports our interpretation of spillover effects.

\subsection{Response of expected economic activity in real time}

Since adverse oil and food supply shocks are known to be detrimental for economic activity, perfectly informed market participants should expect a decline in economic activity after such shocks, in particular in periods when the shocks trigger a stronger increase in the own price, as well as additional unfavorable spillover effects on other commodity prices. In contrast, when there is (more) misperception about the rise in commodity prices, participants should become (more) optimistic about economic activity in the near future, or less pessimistic about the negative impact of higher commodity prices compared to a situation of perfect information.

To evaluate how expectations changed in real time, Fig. 4 shows the time-varying effects of both shocks on several indicators of expected global economic activity that are added one-by-one to the baseline TVP-BVARs. The first row shows the impact on the Composite Leading Indicator (CLI) of the OECD, which is constructed by aggregating leading economic variables of OECD countries that are timely available and not subject to revision. They reflect, inter alia, activity in the early stages of production (e.g. new orders, order books and construction approvals) and private-sector expectations (e.g. stock prices, prices of raw materials, business surveys and confidence indicators). The results are consistent with more misinterpretation in periods of high spillovers: both the rise of spillovers over time and their peak around 2008 are reflected in a more favorable response of the CLI to food and oil supply shocks.

This observation withstands when we estimate the effects on the OECD's Business Confidence Index (BCI) shown in the second row of the figure. In contrast to the CLI, which partly relies on the prices of raw materials, the $\mathrm{BCI}$ is only based on surveys related to production, orders and stocks of finished goods in the industry sector and hence does not mechanically respond to commodity supply shocks. Furthermore, as shown in the bottom rows of Fig. 4, also the responses of equity prices support the hypothesis of misperception. Although the uncertainty of the estimates is relatively large, the MSCI World equity price index (covering developed economies), as well as the MSCI Emerging Markets index reveal an increasingly optimistic interpretation of supply-driven commodity price increases at times of stronger spillover effects. In sum, the time-varying effects of oil and food supply shocks on variables that reflect expectations about current and future economic conditions reinforce the hypothesis that informational frictions have been a major source of spillovers since the 2000s. Again, we are not aware of another mechanism that could explain these time-varying responses.

\subsection{Financialization and the volatility of macroeconomic shocks: quantitative assessment}

Finally, we estimate the extent to which changes in (i) commodity markets financialization, (ii) the volatility of macroeconomic shocks and (iii) the interaction of both phenomena have contributed to the magnitudes of price spillovers. The underlying idea is that more financialized commodity markets should facilitate and encourage information discovery, which could lead to (stronger) spillover effects. Furthermore, as discussed in Section 5.1, in the presence of informational frictions and information discovery in commodity markets, the responsiveness to price signals and thus spillover effects increases when there is (ceteris paribus) a rise in the variance of macroeconomic shocks. Accordingly, spillovers should be particularly pronounced during episodes of high macroeconomic volatility and highly financialized commodity markets. 


\section{A. One Standard Deviation Shock}

Oil Supply Shock

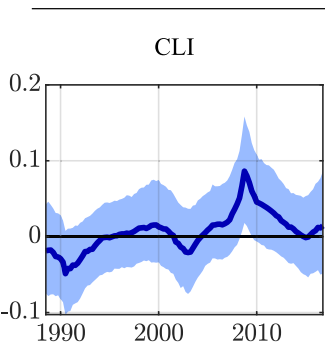

BCI

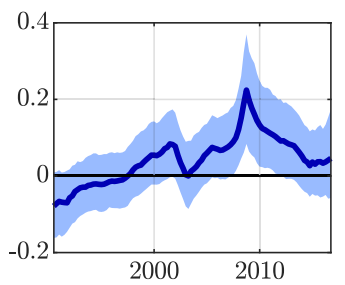

MSCI World

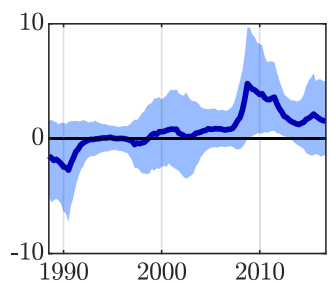

MSCI Emerging Markets

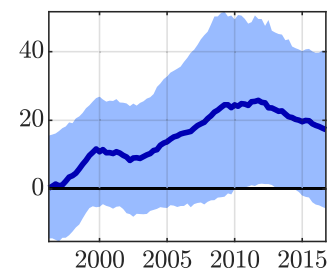

Food Supply Shock

CLI

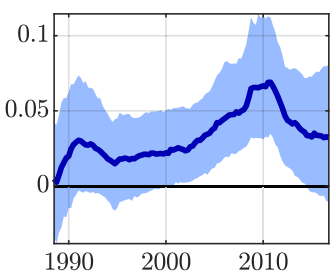

BCI

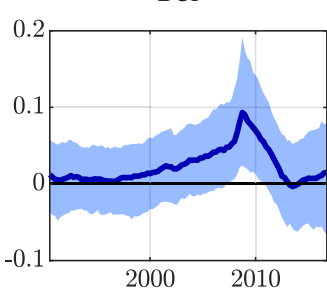

MSCI World

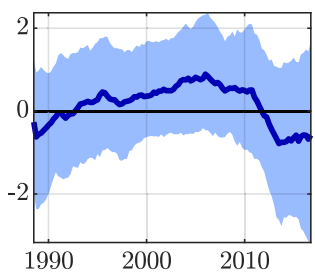

MSCI Emerging Markets

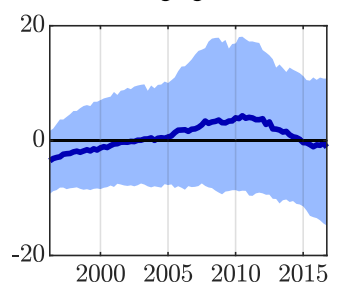

\section{B. Normalized Time Variation}

Oil Supply Shock

Food Supply Shock
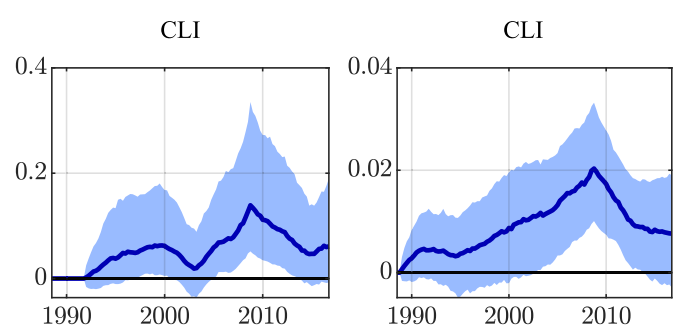

$\mathrm{BCI}$

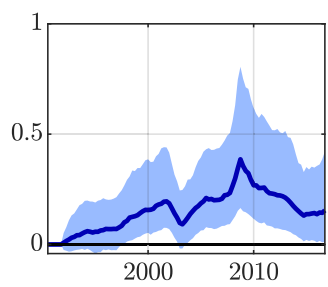

BCI

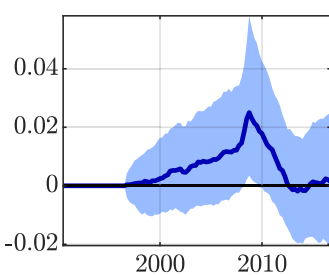

MSCI World
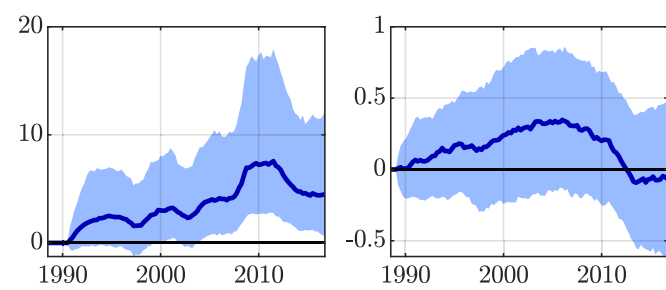

MSCI Emerging Markets

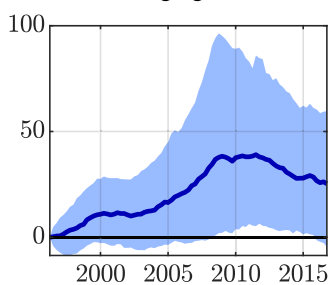

MSCI Emerging Markets

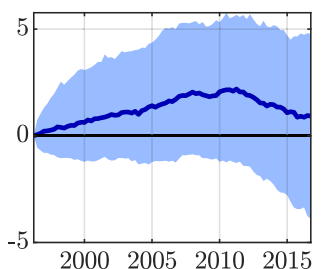

Fig. 4. Time-varying effects of oil and food supply shocks: expected economic activity. Notes: Panel A shows the contemporaneous impact of a one standard deviation shortfall in the production of oil (first column) and food (second column) based on TVP-BVARs. Panel B shows the time variation in these responses, calculated as the change in the contemporaneous response (normalized to represent a 1 percent production shortfall) over time relative to a benchmark quarter. The benchmark quarter is selected as the quarter with the lowest median (normalized) response. Except for the model that features the MSCI index for emerging markets (which uses only two lags due to a substantially shorter sample), these models are estimated using six lags. The additional variables are added one-by-one as a third variable to the prices and quantities of crude oil and food commodities, respectively. The shaded areas are the 16th and 84th percentile credible sets.

To this end, we estimate the following local projections of spillover effects:

$$
\begin{aligned}
\Delta p_{t+h}^{j}= & c_{h}^{i}+\varepsilon_{t}^{i}\left(\vartheta_{0, h}^{i}+\vartheta_{1, h}^{i} \operatorname{vol}_{t-1}+\vartheta_{2, h}^{i} \operatorname{fin}_{t-1}+\vartheta_{3, h}^{i} \operatorname{fin}_{t-1} \operatorname{vol}_{t-1}\right) \\
& +\phi_{1, h}^{i} \operatorname{vol}_{t-1}+\phi_{2, h}^{i} \operatorname{fin}_{t-1}+\phi_{3, h}^{i} \mathrm{fin}_{t-1} \operatorname{vol}_{t-1}+\sum_{l=1}^{p} \boldsymbol{B}_{l, h}^{i} \boldsymbol{y}_{t-l}^{i}+u_{t+h}^{i},
\end{aligned}
$$

where $\Delta p_{t+h}^{j}$ is the growth rate of crude oil $(j)$ or food $(i)$ commodity prices between horizons $t$ and $t+h(h=0,1, \ldots, 4) . \varepsilon_{t}^{i}$ is a series of food or oil supply shocks at time $t$, respectively, which we obtain from the TVP-BVARs. $\sum_{l=1}^{p} \boldsymbol{B}_{l, h}^{i} \boldsymbol{y}_{t-l}^{i}$ reflects $p=6$ lags of the var-

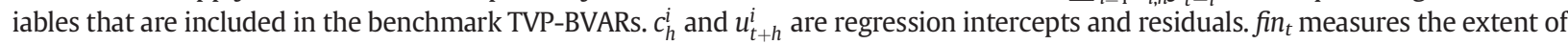


commodity markets financialization, as constructed by Cheng and Xiong (2014) and shown in Fig. 1. This series is a composite index of commodity futures open interest that covers the core commodities of the Goldman Sachs Commodity Index (GSCI). As a proxy for the volatility of global macroeconomic shocks, $\mathrm{vol}_{\mathrm{t}}$, we use the measure of global macroeconomic uncertainty from Mumtaz and Musso (2021), which has been constructed using a dynamic factor model and covers 22 OECD countries. The series, shown in Fig. 1, represents the volatility over time of the unforecastable component of a large set of global macroeconomic and financial variables. An implicit assumption that we make in the estimations is that the (joint) volatility of all other commodity market shocks has been more or less constant over the sample period. Both series, fin ${ }_{t}$ and $v o l_{t}$, are included in the estimations at time $t-1$ to address endogeneity concerns, and standardized prior to the estimations to facilitate the interpretation of the results.

By estimating the local projections, the sum of the $\vartheta_{0, h}^{i}$ coefficients provides average level responses of oil prices to food supply shocks (and vice versa) over the sample. $\vartheta_{1, h}^{i}$ and $\vartheta_{2, h}^{i}$ reflect additional spillovers when the volatility of macroeconomic shocks or financialization are one unit above their sample means, respectively, while the other variable remains at its sample mean. Finally, the sum $\vartheta_{1, h}^{i}+\vartheta_{2, h}^{i}+\vartheta_{3, h}^{i}$ measures the additional price spillovers when the volatility of macroeconomic shocks is above its sample mean during periods when there was also a high degree of commodity markets financialization. The latter is exactly the interpretation of stronger spillovers that we have described in Section 5.1.

The results are shown in Fig. 5. Since the TVP-BVARs render posterior distributions for the shocks, we proceed in two alternative ways to estimate equation 2. First, we collect the medians of the shock series and use these as regressors; where IRF standard errors are heteroskedasticity-robust. Since we use lag-augmented local projections, there is no need to correct for autocorrelation

\section{A. Spillovers of Oil Supply Shocks to Food Commodity Prices}
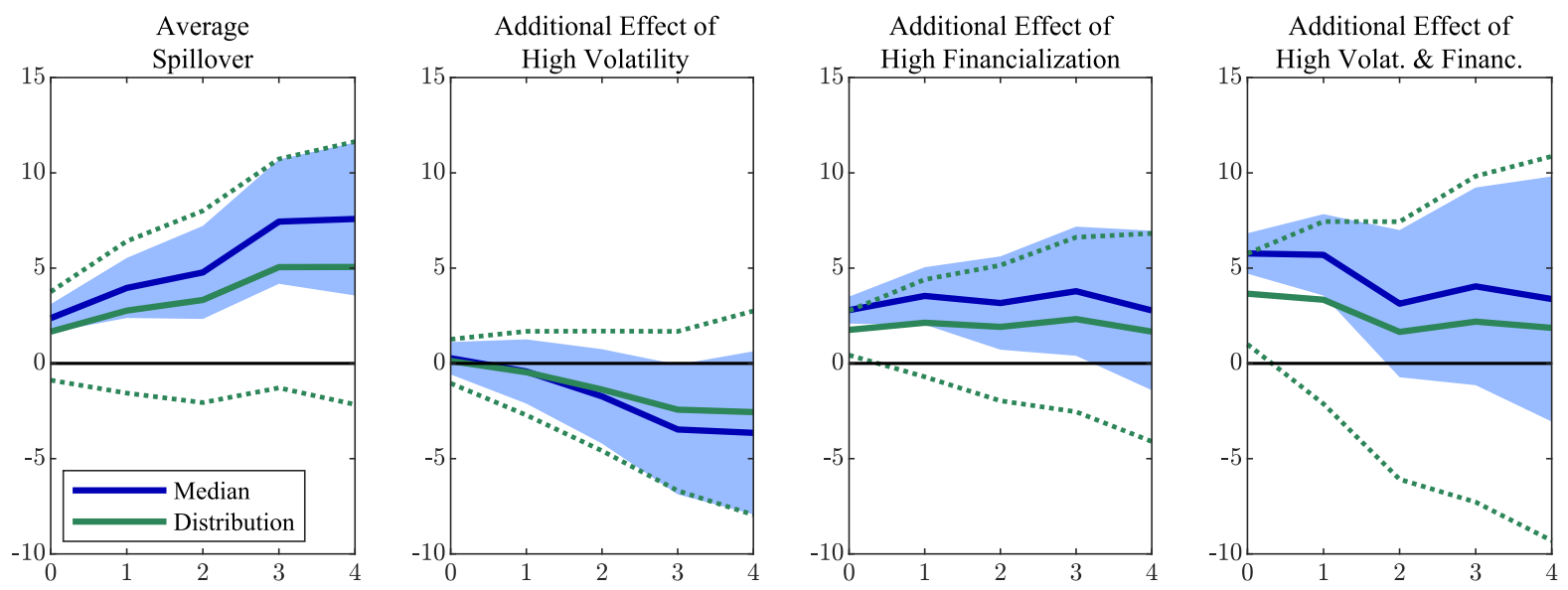

\section{B. Spillovers of Food Supply Shocks to Crude Oil Prices}
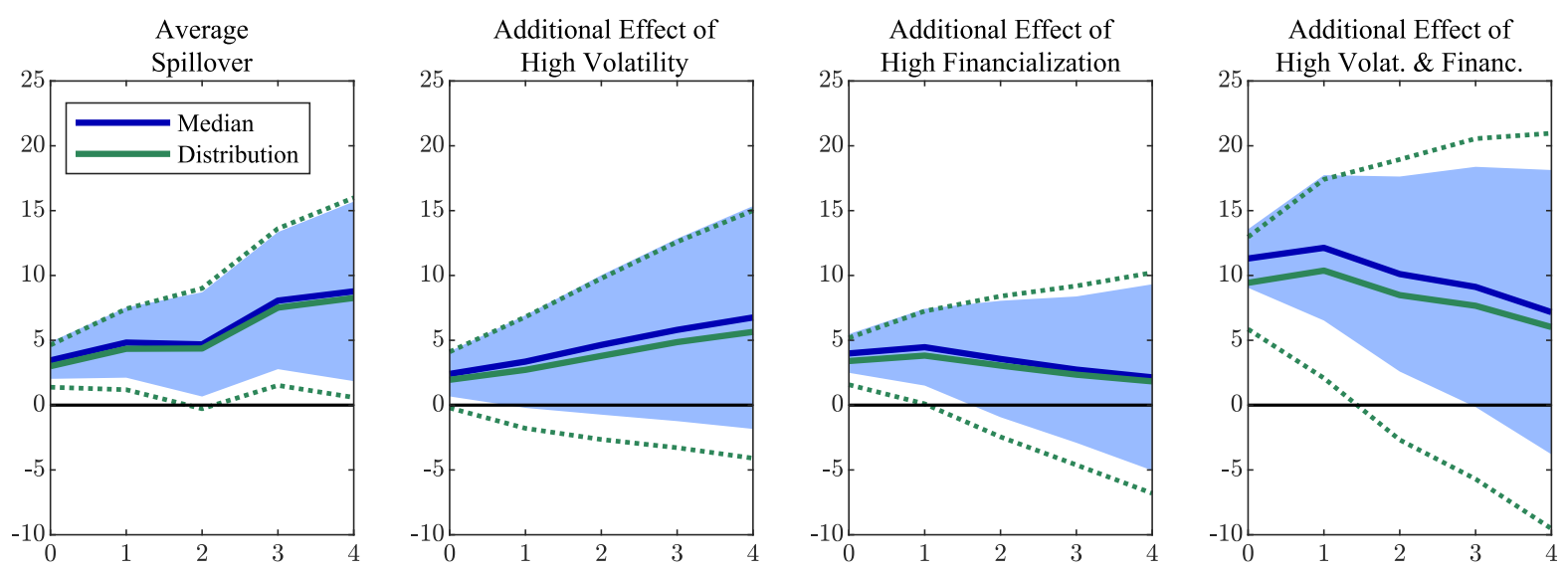

Fig. 5. The role of financialization and macroeconomic volatility for oil and food price spillovers. Notes: The figure plots impulse responses of food and oil prices to an adverse, one standard deviation oil supply (panel A) and food commodity supply (panel B) shock. The blue lines correspond to estimates that are based on the median from the TVP-BVARs' shock distributions, while the solid green lines refer to the median impulse response when we (i) use 1,000 shocks from the posterior distributions and estimate local projections for each of these shocks and (ii) generate 100 draws from a normal distribution for these estimates. Blue shaded areas and dotted green lines represent $68 \%$ confidence intervals/credible sets. (For interpretation of the references to color in this figure legend, the reader is referred to the web version of this article.) 
(see Montiel Olea and Plagborg-Møller, 2021). Second, we perform the estimations for 1,000 individual shock series from the posterior distributions separately. Then, we generate 100 draws of coefficients for each of these IRFs (i) assuming normality and (ii) accounting for the standard error adjustments. Blue lines (surrounded by light blue shaded areas) in Fig. 5 refer to median-based IRFs, while the green solid/dashed lines refer to estimations that are based on 1,000 draws from the posterior shock distributions.

As can be observed in the left columns of the figure, average spillover effects have been positive in the sample period. Furthermore, it appears that elevated levels of macroeconomic volatility or financialization-while the other variable remains at the sample mean-is already sufficient to generate increased price spillovers. The uncertainty of these estimates is, however, relatively high. Most importantly, the local projections reveal that there is a considerable rise in the spillover effects when both the volatility of macroeconomic shocks and financialization are high; that is, elevated levels of macroeconomic volatility in more financialized commodity markets has been associated with stronger spillovers of both oil and food commodity supply shocks on other commodity prices. Ultimately, we demonstrate in appendix D that results are similar for the spillovers to the prices of metals commodities and raw agricultural materials, when we add lags of the financialization and volatility index to the model, when we consider emerging markets instead of global macroeconomic uncertainty or when we extend the model with an indicator of global biofuels consumption. Notably, the biofuels narrative once again falls short in explaining spillovers. Finally, we show that the size of both supply shocks seems not to be important for the magnitudes of spillovers.

Overall, along with the other empirical observations established in this paper, we conclude that the informational frictions hypothesis is strongly supported by the data. In the end, it takes a model to beat a model, and we are not aware of other mechanisms that could explain all these concurrent changes over time.

\section{Conclusion}

Our results provide a number of relevant considerations for practitioners, policymakers and future research. First, even though informational frictions are a plausible explanation for the time variation and spillover effects, the mechanism requires further confirmation. Second, since crude oil and food commodity markets are often subject to supply disruptions, the increased spillovers are important for hedging strategies of commodity producers and speculators' investment strategies. Moreover, since informational frictions appear to be the source of the time variation, the extent of spillovers will likely continuously change over time. Third, our results indicate that this reasoning also applies to the own price elasticity of both commodities. More generally, as argued by Cheng and Xiong (2014), incorporating informational frictions into existing theoretical and empirical models could significantly improve our understanding of commodity market dynamics. Fourth, the presence of spillover effects should be taken into account for many countries' energy and food policies. Notably, our results suggest that biofuels were not the source of the documented spillovers. Finally, our findings are important for monetary policy. In particular, we show in appendix E that food supply shocks do not only propagate via food retail prices to consumer prices in recent periods, but also via energy prices, while oil supply shocks affect inflation via retail prices of food, which was not the case in earlier periods.

\section{Declaration of Competing Interest}

None of the authors have any conflicts-of-interest to disclose.

\section{Appendix. Supplementary information}

Supplementary data to this article can be found online at https://doi.org/10.1016/j.jinteco.2021.103540.

\section{References}

Abbott, P., Hurt, C., Tyner, W.E., 2011. What's driving food prices in 2011? Issue Report July 2011. Farm Foundation.

Avalos, F., 2014. Do oil prices drive food prices? The tale of a structural break. J. Int. Money Financ. 42, $253-271$.

Baumeister, C., Kilian, L., 2014. Do oil price increases cause higher food prices? Econ. Policy 29, 691-747.

Baumeister, C., Peersman, G., 2013a. The role of time-varying price elasticities in accounting for volatility changes in the crude oil market. J. Appl. Econometr. 28, 1087-1109.

Baumeister, C., Peersman, G., 2013. Time-varying effects of oil supply shocks on the US economy. Am. Econ. J.: Macroecon. 5, 1-28.

Cheng, I.H., Kirilenko, A., Xiong, W., 2015. Convective risk flows in commodity futures markets. Rev. Financ. 19, $1733-1781$.

Cheng, I.H., Xiong, W., 2014. Financialization of commodity markets. Annu. Rev. Financ. Econ. 6, 419L 41.

Datta, D.D., Johannsen, B.K., Kwon, H., Vigfusson, R.J., 2021. Oil, equities, and the zero lower bound. Am. Econ. J.: Macroecon. 13, $214-253$.

De Winne, J., Peersman, G., 2016. Macroeconomic effects of disruptions in global food commodity markets: evidence for the United States. Brookings Papers on Economic Activity 47, 183-286.

De Winne, J., Peersman, G., 2021. The adverse consequences of global harvest and weather disruptions on economic activity. Nat. Clim. Change 11, 665-672.

Erten, B., Tuzcuoglu, K., 2018. Output effects of global food commodity shocks. J. Global. Dev. 9, 1-18.

Hamilton, J.D., 2009. Causes and consequences of the oil shock of 2007-08. Brookings Papers on Economic Activity 40, $215-283$.

Hamilton, J.D., Herrera, A.M., 2004. Oil shocks and aggregate macroeconomic behavior: the role of monetary policy: Comment. J. Money Credit Bank. 36, 265-286.

Hassler, J., Sinn, H.W., 2016. The fossil episode. J. Monet. Econ. 83, 14-26.

Hertel, T.W., Beckman, J., 2012. Commodity Price Volatility in the Biofuel Era: An Examination of the Linkage between Energy and Agricultural Markets. In: Joshua, S. Graff Zivin, Jeffrey, M., Perloff (Eds.), volume The Intended and Unintended Effects of U. S. Agricultural and Biotechnology Policies. University of Chicago Press. Lombardi, M.J., Van Robays, I., 2011. Do financial investors destabilize the oil price? ECB Working Paper Series 1346

Miescu, M.S., 2019. Uncertainty shocks in emerging economies: a global to local approach for identification. Lancaster University Economics Working Paper Series 2019/017. 
Montiel Olea, J.L., Plagborg-Møller, M., 2021. Local projection inference is simpler and more robust than you think. Econometrica 89, $1789-1823$. Mumtaz, H., Musso, A., 2021. The evolving impact of global, region-specific, and country-specific uncertainty. J. Bus. Econ. Stat. 39, 466-481.

Peersman, G., 2021. International food commodity prices and missing (dis)inflation in the euro area. Rev. Econ. Stat. (forthcoming).

Primiceri, G.E., 2005. Time varying structural vector autoregressions and monetary policy. Rev. Econ. Stud. 72, 821-852.

Serra, T., Zilberman, D., 2013. Biofuel-related price transmission literature: a review. Energy Econ. 37, 141-151.

Singleton, K.J., 2013. Investor flows and the 2008 boom/bust in oil prices. Manage. Sci. 60, 300-318.

Sockin, M., Xiong, W., 2015. Informational frictions and commodity markets. J. Financ. LXX, 2063-2098.

Tang, K., Xiong, W., 2012. Index investment and the financialization of commodities. Financ. Anal. J. 68, 54-74.

Tyner, W.E., 2010. The integration of energy and agricultural markets. Agric. Econ. 41, 193-201.

Wu, J.C., Xia, F.D., 2016. Measuring the macroeconomic impact of monetary policy at the zero lower bound. J. Money Credit Bank. 48, $253-291$. 